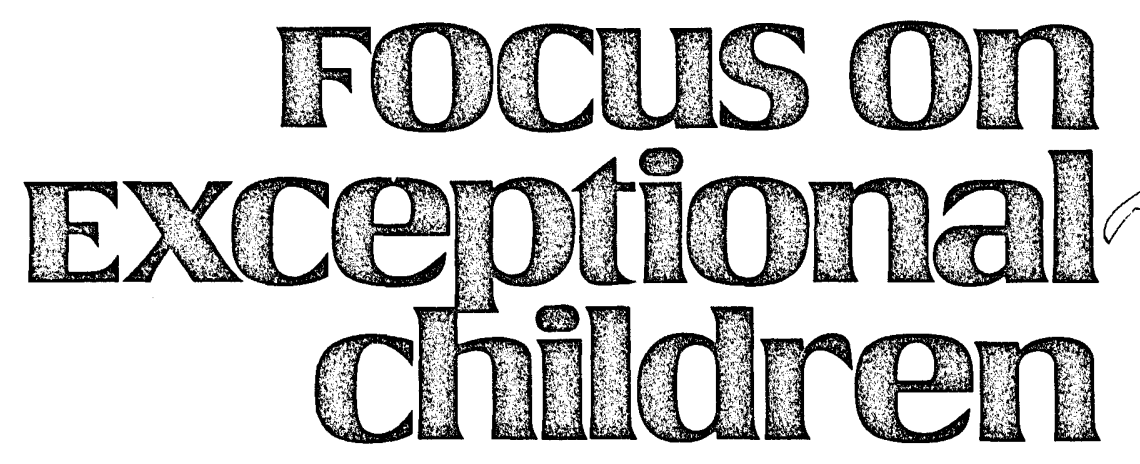

\title{
Teaching Children to be Independent Learners: A Step-by-Step Strategy
}

\section{Sandra Cohen and Laurie de Bettencourt}

The introduction and maintenance of mildly handicapped children in regular classrooms has pointed up the need for special education resource teachers to reconsider classroom management and teaching strategies. One aim of this article is to isolate and evaluate procedures that enable regular education teachers to provide the greatest amount of personalized attention to the greatest number of students. Considering the limitations of large regular class sizes, increasing curriculum scope, complex support service schedules, and specified academic programs, individualized teaching is no easy matter today.

The heterogeneity of today's classroom can result in an extremely frustrating situation for the classroom teacher who sincerely wants to help children function at their own level and pace. Common statements among teachers working in mainstreamed settings include:

- I need more time-The time passes by so quickly.

-I have added responsibility toward just one student, and that may take time (instruction) from others.

- Too much attention is given to the handicapped child at the expense of others.

-I now need to adjust strategies to meet each child's needs.

- I'm not trained to teach handicapped children or to deal with such a range of problems. (Schwartz, Schwartz \& Cohen, 1979)

A thread that seems to run through these concerns is: "How can the teacher give each child the attention needed within a day's time limit?" In many cases, classroom teachers are turning to special educators for approaches that will allow them to resolve this problem. Resource teachers are beginning to help classroom teachers understand that the answer to this dilemma is in the management of individual students' behaviorsresulting in their becoming independent learners. The special educator should be able to instruct the classroom teacher in specific procedures that will enable all children, including slow learners, to work independently.

Sandra Cohen is an associate professor and Laurie deBettencourt is a graduate research assistant, both in the Department of Special Education, University of Virginia. 
The special educator, in serving classroom teachers who are involved in mainstreaming, should provide consultative services including: (1) feedback on student progress, (2) information related to teaching skill development, (3) support for personal efforts, and (4) assistance in program development and documentation. Within the last category a wide range of services can be established, but the emphasis should be on creating organizational and programmatic components that will allow problem learners to fit within the functioning sphere of the regular classroom routine. A graphic illustration of this concept, given in Figure 1, depicts the ultimate goal of consultation: to include mildly handicapped learners within the regular classroom.

Children who are able to work without continuous supervision allow the teacher to spend time in more direct instruction. Becker and Carnine (1981) compared several instructional programs and found that students involved in direct instruction programs made the most overall academic gains. The direct instruction approach is built on the behavioral model of teaching, in which students are

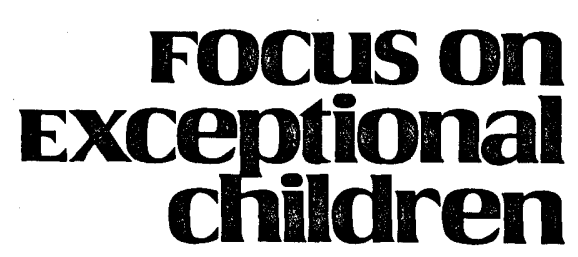

FOCUS ON EXCEPTIONAL CHILDREN (ISSN 0015-511X) (USPS 203-360) is published monthly except June, July, and August as a service to teachers, special educators, curriculum specialists, administrators, and those concerned with the special education of exceptional children. This journal is abstracted and indexed in Exceptional Child Education Resources, and is also available in microform from Xerox University Microfilms, Ann Arbor, Michigan. Subscription rates, $\$ 18.00$ per year. Copyright () 1983, Love Publishing Company. All rights reserved. Reproduction in whole or part without written permission is prohibited. Printed in the United States of America. Second class postage is paid at Denver, Colorado. POSTMASTER: Send address changes to:

Love Publishing Company

Executive and Editorial Office

1777 South Bellaire Street

Denver, Colorado 80222

Telephone (303) 757-2579

\section{EDITORIAL BOARD}

Edward L. Meyen

University of Kansas
Glenn A. Vergason Georgia State University
Richard J. Whelan University of Kansas Medical Center

\section{Pre-Consultation}

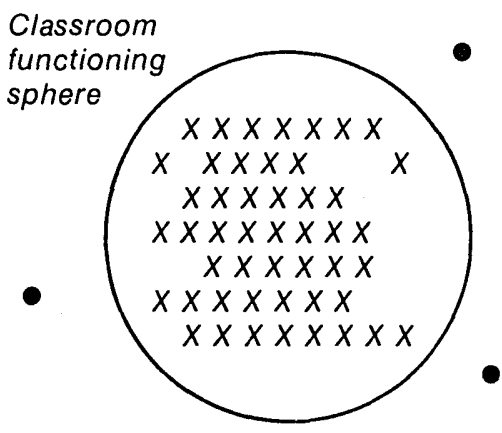

Post-Consultation

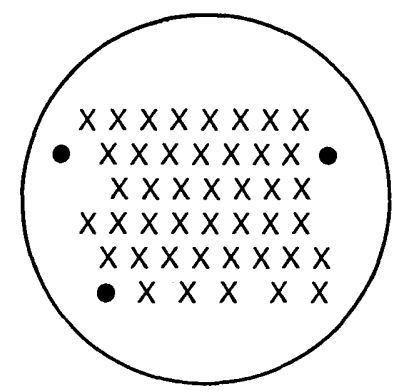

- mildly handicapped child

FIGURE 1

Regular Classroom Inclusion Sphere

STATEMENT OF OWNERSHIP, MANAGEMENT AND CIRCULATION

Date of Filing: September 13, 1983

Title of Publication: FOCUS ON EXCEPTIONAL CHILDREN

Frequency of lssue: Monthly except June, July, and August

Location of Known Office of Publication: 1777 S. Bellaire St., Denver, CO 80222

Location of Headquarters of Publisher: 1777 S. Bellaire St., Denver, CO 80222

Name and Address of Publisher, Editor, and Managing Editor: Stanley F. Love 1777 S. Bellaire St., Denver, CO 80222

Owner. Stanley F. Love

Extent and Nature of Circulation:

Average No. Copies Each Issue during Preceding 12 months

Total No. Copies Printed

4,717

Filing Date

Paid Circulation

Sales thru Dealers, etc.

Mail Subscriptions

Total Paid Circulation

Free Distribution

Total Distribution

Office Use and Left Over

Total
4,200

0

3,748

3,748

300
4,048

4,048

152
4,200

I certify that the statements made by me above are correct and complete. 
taught to work independently, allowing the teacher to spend more time on small group instruction. This arrangement enables a teacher to work with groups of children in initial skill training, to provide remedial assistance, and to facilitate learning programs while the individual child pursues his/ her own assignments. Embedded within this structure are procedures to facilitate learning at various achievement levels.

To reach the objective of managing a range of ability levels and to enable each child to function for specified time periods without direct teacher attention, a systematic approach toward developing independent learners is necessary. Independent learners reap the benefits of using time productively, developing a better self-image through personal management, and establishing learning strategies that will be helpful throughout school. Independent learning skills are not child-specific; they are not possessed only by children of certain personality traits, backgrounds, or intellectual levels. All children can be taught to work independently through a step-by-step strategy.

\section{A MODEL FOR STUDENT AND TEACHER RESPONSIBILITIES}

To establish an effective program, two sets of responsibilities must be considered: student task responsibilities and teacher task responsibilities. The two units of task responsibilities are interdependent and should develop concurrently. The teacher's segment creates the framework within which the student carries out the specific components leading to independent task completion.

\section{Student task responsibilities}
a. Following directions
b. Approaching tasks
c. Obtaining assistance
d. Gaining feedback
e. Gaining reinforcement

2. Teacher task responsibilities
a. Materials organization
b. Work areas
c. Time constraints
d. Task transitions

\section{Student Responsibilities}

\section{Following Directions}

For the majority of independent learning activities, the child is expected to follow written directions-a complicated task for the youngster with reading difficulties. The most commonly used instructions incorporate approximately 15 key words or phrases. These appear over and over again in a wide variety of assignments, and a child's failure to decode them often underlies incompletely or inaccurately done tasks. Each of these terms and a simple rebus code are provided in Figure 2.

The direction words and their associated picture stimuli should be clearly posted in the room for quick reference whenever necessary. Other significant words may be added to the list whenever appropriate for class activities. The procedure specified for instruction would remain the same no matter what words were substituted. Through this strategy the child learns to respond to a specific picture stimulus and to carry out the simplified directions.

The next step is to transfer the child's attention from the picture to the actual direction word. This is done through the systematic fading procedure given in Figure 3. The picture stimulus is gradually transferred to the word so the child can successfully read the printed direction. The directions should be kept simple until the child has mastered the basic elements.

Attention must also be given to adjusting commercially made materials so problem readers can follow the directions. By adapting materials, the teacher expands the range of consumers, individualizes instruction, and trains students to work more independently. Some suggestions for adapting commercial materials are:

1. Use picture directions. Teach key words in directions using rebus symbols until the child is able to follow these directions independently. Then gradually fade the pictures into actual word directions.

2. Use a tape recorder. Record directions on tape. The student can replay the tape to comprehend difficult directions.

3. Simplify written directions. Highlight or underline significant parts of the directions. Or rewrite the directions to include only the significant parts, expressed in a simpler form.

4. Reduce extraneous stimuli. Use line markers or page covers to block out unnecessary parts of the direction statement. This helps the child focus upon the essential components of the direction.

5. Vary response forms. Change a response mode that is difficult for a particular learner. For instance, ask a child who has trouble with handwriting to circle or underline to indicate the response.

6. Clarify directions. Following a directional sequence 


\section{Direction Word}

1.

2.

3.

4.

5.

6.

7.

8.

9.

10.

11.

12.

13.

14.

15. circle

cross out

book

read

page

cut

color

look (at; over)

listen

underline

do

write

think

tape (record)

remember
Picture Stimulus
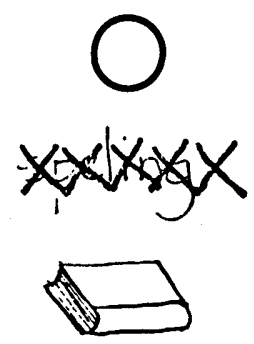

○) 慉

$P$

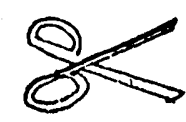

$\longrightarrow$ rayda

$\omega<$

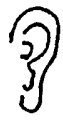

written

do

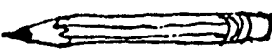

$$
=
$$
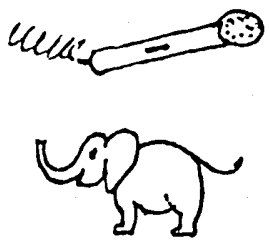
Step 1: Introduce 2-4 oral word direction words and their picture stimuli (rebus) at a time.

Step 2: Practice rebus directions until the child is able to use them correctly in 10 successive trials.

Step 3: Use rebus symbol to give directions on student assignments.

Step 4: Associate rebus and written direction word in practice list.

Step 5: Associate rebus directions and written directions on assignments.

Step 6: Fade rebus while highlighting the written word direction.

Step 7: Present written directions but allow the child to find uncertain words on class rebus poster, if necessary.

\section{Sample Step Fading Procedure}

Step 1: Look

Step 2: Teacher: This word is $(\bigcirc$ ) circle.

What is this word? (point to $\bigcirc$ ).

Class: Circle.

Teacher: Good-circle.

Again (point to $\bigcirc$ ).

Class: Circle.

Teacher: Yes.

Here are two words: $\triangle \bigcirc$

Teacher: Show me circle.

Class: (Points to circle.)

Step 3: $\bigcirc \underline{A}$ words

Repeat varying stimuli until class (child) can identify circle 10 times out of 10.

Circle $\underline{A}$ words

Step 4: Rebus

Word

circle

Teacher: Class, what is this word? (point to the word circle).

Class: Circle.

Teacher: Yes, this word is circle.

Step 5:

p. $6+$ ? m mux $=0$

Read page 6 and listen to tape.

- words ? мими $\rightleftharpoons$

Circle the words you hear on the tape in the book.

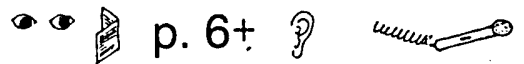

Read page 6 and listen to the tape.

0 words ? мима $\rightleftharpoons$

Circle the words you hear on the tape. 
can be a problem for some learners.

a. Have the child repeat the directions to check for understanding.

b. Paraphrase the directions and provide an appropriate example.

c. Repeat the directions while the child is working on an example.

Adhering to the simple rules listed below will allow the student to develop a more accurate expectation of the task:

- Keep directions short.

- Present directions clearly.

- Highlight relevent information.

- Specify what to do when finished.

- Specify time limit.

\section{Approaching Task}

Often a student can perform a task but does not approach the task systematically, resulting in time lost while getting started on each assignment. If the teacher is working with a small group in another section of the room, it is distracting and time consuming to constantly cue a student for each response. Teaching the child a systematic task approach can be accomplished using a step-by-step sequence that helps the child structure behavior. The procedure consists of asking oneself a series of questions listed on a Job Card (see Figure 4). Before beginning a task, the independent worker figures out what has to be done to complete the task, where the necessary materials are, the appropriate place to do the assignment, how much time is available for the activity, and what should be done after completing the assignment.

Success in teaching the student to approach a task independently requires initial teacher time and consistent teacher behavior. Children who have always depended on teachers to lead them through the day will continue to solicit unnecessary assistance and will be reluctant to change old habits. Independent work skills have to be consistently reinforced.

In some cases getting together the necessary materials to begin a task is not the problem, but deciding what to do to perform the task independently and correctly is a problem. Strategy training procedures are designed to help students approach or attack school learning tasks in systematic ways (Lloyd, 1980). In strategy training students are taught to use simple, direct systems for approaching different tasks. Generally, a strategy training approach to instruction includes four steps:

1. Define a group of related problems that you want the student to be able to solve.

2. Identify a step-by-step procedure (strategy) for solving the problems.

3. Specify the skills required by each of the steps in the strategy.

4. Assess the student's performance in each of the component skills, and separately teach component skills not mastered.

The exact nature of the strategy will depend on the attributes of the learning task.

DO I KNOW THESE THINGS?

1. What do I need?

2. Where is it?

3. Where should I work?

4. How much time do I have?

5. What do I do with my work and myself when I'm done?

\section{FIGURE 4} Job Card

Strategy training has been found to be an effective means of teaching essential academic skills and an effective means of building independent skills in students (Carnine, Prill, \& Armstrong, 1978; Kameenui, Carnine, \& Maggs, 1980; Lloyd, Saltzman, \& Kauffman, 1981). To employ strategy training procedures in your classroom requires extra initial time in setting up the tasks, but it will save a great deal of time over the long term.

\section{Obtaining Assistance}

Before the student can work independently, a support system must be developed to provide assistance and prevent or reduce frustration. The assistance component is of primary importance during the initial independent learning period when a new skill is being introduced and 
practiced.

Situations in which children may need assistance are:

-Assistance in decoding a word.

-Explanation of an uncertain concept.

-Clarification of a response that differs from the provided answer key, and stimulus cues or prompts.

- Reminder of appropriate problem strategy.

The student could select from several alternative approaches to gain assistance when a task problem arises. One procedure is to sign up for a teacher-pupil conference (see Figure 5). This is most successful when the child does not need immediate help. For example, if the child has checked his or her responses using a self-correction device and is somewhat confused in applying a concept (e.g., regrouping), the teacher-pupil conference offers time for further one-to-one teaching of the concept. Using this approach, assistance is aimed at eliminating confusion and preventing future failure.

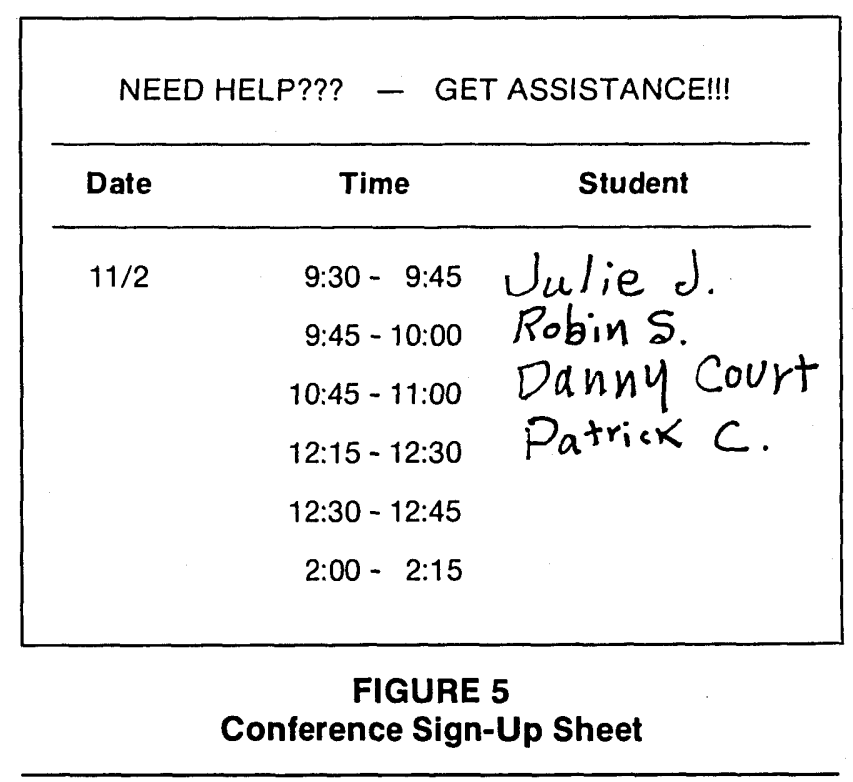

Another alternative, one that can provide more immediate help for preventing frustration as the task continues, is peer tutoring. In this approach the child consults with another pupil who has previously mastered the skill or concept. When using peer tutors, the teacher must assume responsibility for the instructional plan. The teacher determines the skills to be reviewed, the materials to be used, and the instructional activity to be employed.
The teacher must also have a system for monitoring its progress so that problems can be swiftly identified and solved (Gerber \& Kauffman, 1981).

Some guidelines for the use of peer tutoring are outlined below.

1. Create the proper mental set: "Everyone needs help sometime." This will reduce competition (peer tutoring is a support program, not a competitive sport).

2. Work out procedural details such as:

- time periods.

- specific assignments.

- tutoring dyads that last one to two weeks so that pairs do not become too entrenched in their roles.

- never having tutors administer real tests.

- starting off slowly.

- planning so that everyone can be a tutor at some time.

- carefully selecting tutoring pairs (don't put best friends or worst enemies together).

- training tutors to use reinforcement and to provide feedback.

- informing parents of program development.

3. Organize by:

- giving clear directions to each tutor.

- establishing rules to be followed by each participant.

- presenting planned activities for the tutoring sessions.

Still another approach that allows the independent learner to gain assistance is for the teacher to provide materials that cue a correct response when the child is uncertain. An example would be a number triangle (Figure 6) for children who are learning simple computation, or a material that cues left and right sides of the room for children who are learning directionality.

The cloze procedure, when applied to instruction rather than diagnosis, is another technique that can aid the problem learner in selecting an appropriate response. Some examples are:

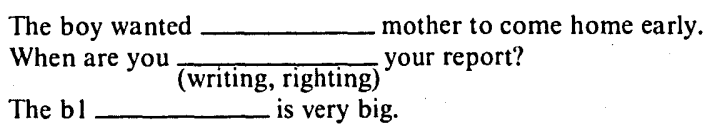

Prompts provided within the learning material can be removed gradually as the problem learner gains competency in the skill. 


\section{Gaining Feedback}

Children who work independently on completing a task should have a means to check their work. Immediate feedback has the advantage of providing opportunities for self-correction. Research (e.g., Graham \& Miller, 1979) has shown that structured self-correction is an extremely important factor in learning rote memory tasks. Feedback can be gained independently through self-checking materials.

To the extent that material provides instruction and allows the child to determine correct versus incorrect responses, it can be considered a teacher substitute. Mercer and Mercer (1978) have suggested that feedback devices:

- Provide immediate response confirmation.

- Reduce failure experiences by reducing the chance of incorrect response practice.

- Maintain the child's attention to the task longer.

A brief listing of self-correcting techniques is provided below:

Flash cards. A problem is presented on one side of a stimulus card, and the answer is placed on the other side.

Matching picture cards. Sets of cards are prepared with the problem on one card and the answer on another card. The back of the set of cards contains a picture. When the student chooses an answer, he or she turns over the cards. If the appropriate answer is chosen, the pictures on the back of the cards fit together to complete a scene.

Puzzle. Pieces of material fit together to indicate a match or correct answer. The top or side of each puzzle shows an object or problem, and the bottom or the other side provides the name of the object or the answer to the problem. The sections will interlock only if they belong together.

Pockets. Pockets may be made easily of envelopes stapled to the back of the learning material (e.g., game board). Pockets may hold the answer key or may be coded to provide feedback.

Cards with holes. Problems are written on one side of a card or sheet, and a hole is punched beside or underneath each item. The answer to each problem is written on the back of the card next to or under the hole. Students may use this learning material in pairs. The student who supplies the answer sticks a pencil through the hole, and the other student checks to see if it corresponds with the correct answer.
Flap. A flap may be made of paper or other material and affixed to the page or sheet. The student can check his or her response by lifting the flap to reveal the answer.

Windows. Small squares may be cut in materials, leaving one side uncut so the window may be open or

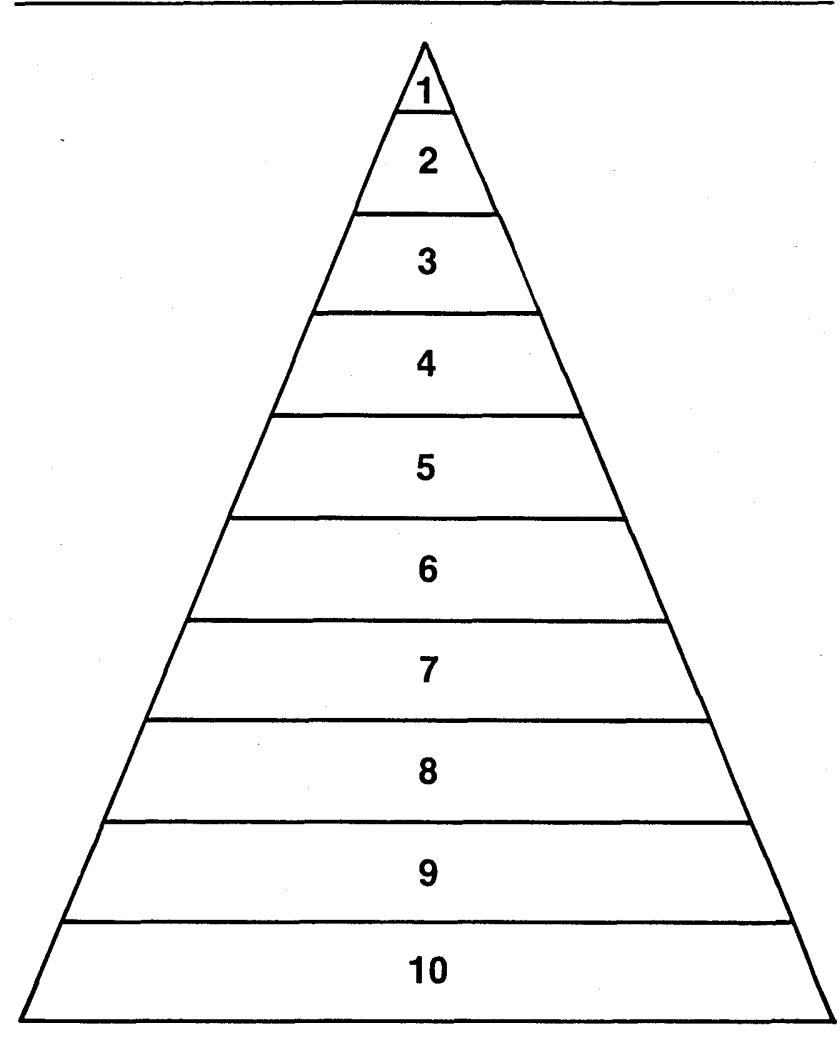

When adding two digits, the student puts a marker under the smaller digit and moves down the same number of spaces as the second addend. For subtraction, the student places the marker under the larger number and moves up the number of spaces designated by the smaller digit. This device is similar to the number line, but it has the added advantages of showing size relationships and providing an alternative for children who have had trouble with traditional number lines.

\section{FIGURE 6 \\ Addition and Subtraction Number Triangle}

closed. The correct answer appears in the open window.

Overlays. The correct response is clearly marked on a transparency. The child places the transparency on top of his or her work to check the answer. This is especially useful for written letter forms, designs such as dot-to-dot puzzles, and structured worksheets with specific spaces for answers. 
Answer tapes. The child listens to a cassette or Language Master tape with the correct answers while checking his or her own answers on paper. This is a good means of providing an alternative mode of input.

The often heard criticism of using self-correcting materials is that, contrary to becoming independent learners, children begin to rely on the answers and do not progress in achievement. This is a strong allegation but not necessarily well-founded. Self-correcting material as a means of providing corrective feedback has been documented recurrently as an effective procedure (Kazdin, 1980).

In most cases, children use answer sheets and other correction devices in much the same way adults use dictionaries to confirm spellings of uncertain words. Finding the correct answer when it is unknown or checking accuracy is an intelligent learning procedure, especially for initial skill learning and during early practice.

The teacher should be alert, however, to children who seem uncertain of their ability over an extended period of time and confirm each response before going on to the next problem. Perhaps the material is too difficult and the teacher should check the child's prerequisite skill level. If this seems to be clearly established, the child should be taught the skill under a different approach. Other children who seem overly reliant upon the checking procedure may need only to gain confidence in themselves. Many mildly handicapped children are so doubtful about their learning ability that they may erase or cross out a spelling word many times, trying a variety of letter patterns and being confident in none.

\section{Gaining Reinforcement}

Upon completing the assigned task, the independent learner should receive reinforcement that does not require direct teacher interaction. Like the other steps in the independent learning sequence, reinforcement should be predetermined and child-initiated. All reinforcement should be based upon an acceptable reinforcement menu-a list of appropriate reinforcements created by the teacher with student input-and should be accessible to the student upon completion of the task. If reinforcement is part of a task routine (e.g., a math worksheet), the learner must understand the reinforcement format (e.g., progress graph) before beginning the task.

A student who has progressed to administering selfreinforcement evidences a level of self-evaluation, motivation, and confidence. In the end, the self-reinforcer is able to instigate and sustain task orientation and to achieve great satisfaction.

A variety of alternative reinforcement systems can be instituted at the culmination of student-directed assignments. Following are only a few of the possibilities for student reinforcement:

- Using tokens governed by specific rules for dissemination (see Sulzar-Azaroff \& Mayer, 1977).

- Charting a progress graph (see Lloyd \& deBettencourt, 1982).

- Plotting a student profile (see White \& Liberty, 1976).

- Initiating instructional contract rewards (e.g., free time).

\section{Summary of Student Task Responsibilities}

Frequently, students are unable to initiate even the simplest beginning steps of a task; or they begin a task appropriately but do not persist long enough to complete assignments. These students need to become independent workers capable of self-monitoring behavior. By learning to monitor behavior, students will remain on-task and, thus, will improve their attending skills. A summary of steps for training independent work skills is given below.

1. Create a specific time for training.

2. Set aside two blocks of time, 30 minutes each.

3. Provide a folder of seatwork that can be completed with $100 \%$ accuracy. (Initially the focus is on teaching students to work independently, not teaching the students new academic skills.)

4. Explain to the students what "working hard" means.

5. Post five or six class rules as a reminder of how a student works hard (e.g., starting work right away, minding your own business, keeping at work, raising your hand if you have a question).

6. Model what a good worker should do.

7. Differentially reinforce the desired behaviors.

8. Gradually increase the amount of time the children are expected to work independently without praise.

9. Initially break the 30-minute time period into smaller segments that vary in length (e.g., Session 1: $3 \mathrm{~min}$., $5 \mathrm{~min}$., $7 \mathrm{~min}$., $4 \mathrm{~min}$., $6 \mathrm{~min}$., $5 \mathrm{~min}$.).

10. Set a timer for the first small segment, and have the children begin their work.

The first step in training independent work habits and self-monitoring of these habits is to set aside a specific 
time for skill development. The most ideal time is early in the day, as this will eventually be the time when teachers most often want students to work independently. An estimated time frame of approximately 30 minutes is appropriate.

The teacher must establish what is meant by "working hard" in the classroom. This can be done by explaining it verbally while modeling the behaviors for the students. Behaviors that indicate "working hard" may include starting work and eyes on your own desk.

In training the student to attend to independent tasks, the desired independent work habits must be reinforced. At first this should be on a continuous schedule, and then intermittently.

\section{Teacher Task Responsibilities}

The teacher must create the framework within which the student carries out the independent learning task. In doing this, the teacher focuses upon establishing the appropriate structured environment and training and supervising the independent learner. Structuring features to be considered include: designation of materials and their location; optimal work space; time constraints; and task transitions from one activity to the next. Preparation of the classroom environment and materials may at first seem time-consuming and tedious but, once again, the initial time investment is small in comparison to the time saved in direct teacher attention.

\section{Materials Organization}

Each learning activity or task should be clearly labeled so that the child knows exactly what materials are needed to successfully complete it. This eliminates unnecessary teacher interruptions and student talk. Less time is needed to complete tasks if all the materials required have been located before attempting to begin the work.

Teacher-made activity cards or spirit duplicating masters can be permanently marked to specify the necessary materials (see Figure 7). Likewise, commercially obtained materials can be easily adapted by systematically adding a "Materials Needed" section to each kit or component. Duplicate lists of commonly used materials can be cut and clipped to various worksheets, learning activity cards, or student contracts. By circling the needed materials for each activity, the master list eliminates the repetitive labeling of similar materials.

crayon
scissors
pencil
counting sticks
glue
dice

spinner paper markers dot board

worksheet no.

Materials needed to complete independent tasks can be made easily accessible by devising a system for coding and grouping materials in the classroom. Here are some ideas:

1. Use a small file box to categorize all classroom materials. This serves as the master file, with each card specifying a material, the objectives, the

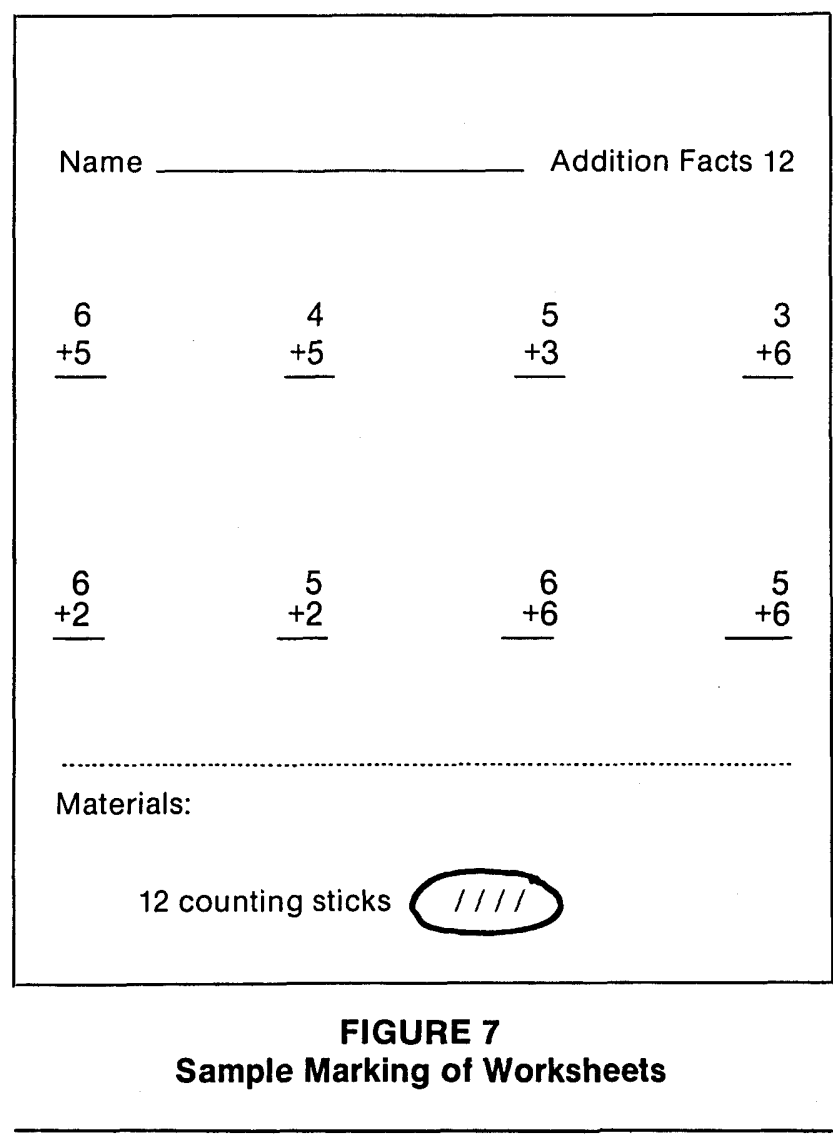

approximate level, and possible adaptations.

2. Develop a material code to specify the type of activity. For example: \ Workbook; - spirit duplicating sheet; $\star$ group name; and $\mathbf{m}$ tape. Label each material with the appropriate code.

3. Divide materials according to levels, and assign the level number along with the material code. 
Example: 4 (ditto, level 4).

4. Organize materials in separate locations for various skill areas (e.g., math, spelling). This also may be done by color coding different subjects.

5. Use the codings and material labels to assign work tasks. A student needing to do a reading cassette tape might be given an assignment sheet with a red (for reading) 6.2 (tape) and $\bullet 6.3$ (supplemental ditto).

Children cannot be expected to work independently if they have to depend on teacher assistance before getting started on a task. Books about learning centers are excellent sources for ideas or techniques for logically arranging materials for easy accessibility.

\section{Work Areas}

For almost every learning activity there is an optimal place in the classroom for each child to accomplish the task. In most instances, children can make the choice based on their own experiences or on classroom rules. An activity that requires a tape player, for example, may be limited to an area in the classroom where this can be set up and used without distraction. Other activities may require a large table where construction paper, glue, and scissors are kept and work space is ample. Independent reading or writing tasks may suggest the use of a carrel or desk set apart from the other students. Movable shelves or bookcases are sometimes used to separate work spaces from the main area of instruction. Children's expressed preferences for a work area may also include working on the floor in a carpeted area, leaning against a wall, writing their responses on the chalkboard rather than a worksheet, and opting to work in the library or other school designated space.

Classroom rules that the class has agreed upon may limit the choices of where children can work. For example, if the class has agreed that all cutting and pasting is to be done only at a certain table, the best place to do this activity has already been determined. Ideally, children should be able to make the decision on work space for themselves as they become more independent learners.

\section{Time Constraints}

Before they begin work, children need to know the time constraints for completing activities. This encourages the independent learner to self-pace and prioritize work. Labeling each learning activity with the time estimated for completion gives children a sense of what self-pacing means. Setting time limits slows down impulsive workers while making the slower workers aware that time is passing.

Time structuring can be achieved by stamping each activity with a set time or by scheduling the completion of several activities at the end of a larger time block. The method selected depends on teacher/student preference, amount of independence previously demonstrated, and scheduling demands.

\section{Task Transitions}

Self-structuring of behavior as an independent learner does not end with completion of a task. The final steps are (1) to place the completed work in a designated area and (2) to prepare for the next activity. Valuable classroom learning time is lost as children make unstructured transitions between activities. Children who have to be reminded what to do next disrupt the classroom activity flow. Transitions can be managed through methods such as by specifying directions, charting movements, and assigning students to act as task monitors.

The teacher should be sure to include these last two steps in the independent learning program. To stress the importance of placing completed work in the proper place, misplaced work should not be graded. Daily instructional time is wasted if desks, folders, and baskets have to be searched for missing work. To avoid having to remind children of what to do next, the teacher should present clear directions and check to be certain that each child knows what activity to turn to upon completing each task.

\section{Summary of Teacher Task Responsibilities}

The classroom teacher's responsibilities involve training the student to become an independent learner and structuring the environment in which the student carries out each learning task. By structuring the environment, the teacher prevents the student from wasting valuable instructional time in transition from one task to another.

Components involved in arranging the classroom environment include organizing materials, determining work areas, designating time constraints, and programming transitions. These features should be clearly introduced and explained to each student. As in any other training, students should be reinforced for following the structure provided. By incorporating the above components into a classroom routine, the teacher is programming for efficient, independent learning. 


\section{REFERENCES}

Becker, W.C., \& Carnine, D.W. Direct instruction: A behavior theory model for comprehensive educational intervention with the disadvantaged. In J.W. Bijou \& R. Ruiz (Eds.), Behavior modification: Contributions to education. Hillsdale, NJ: Erlbaum, 1981.

Carnine, D.W., Prill, N., \& Armstrong, S. Teaching slower performing students general case strategies for solving comprehension items. Eugene, OR: University of Oregon Follow Through Project, 1978.

Gerber, M., \& Kauffman, J.M. Peer tutoring in academic settings. In P.S. Strain (Ed.), The utilization of classroom peers as behavior change agents. New York: Plenum, 1981.

Graham, S., \& Miller, L. Spelling research and practice: A unified approach. Focus on Exceptional Children, 1979, 12, 2, 1-16.

Kameenui, E.J., Carnine, D.W., \& Maggs, A. Instructional procedures for teaching reversible passive voice and clause constructions to three mildly handicapped children. Exceptional Child, 1980, 27(1), 29-41.

Kazdin, A.E. Behavior modification in applied settings (2nd ed.). Homewood, IL: Dorsey, 1980.

Lloyd, J. Academic instruction and cognitive behavior modification: The

\section{Professional update}

\section{NEW BOOK}

\section{Dealing With the Unexpected: A Situational Approach for Teachers \\ by Stuart E. Schwartz}

This practical book is essentially a collection of simulations to prepare teachers to better confront and handle unexpected situations. The worksheet format encourages users to give their reactions on how they would handle the situation. For example: While class is in session, you notice that three of the students seem to be occupied with something other than their assigned work. As you walk down the aisle, you observe the three hiding a need for attack strategy training. Exceptional Education Quarterly, $1980, I(1), 53-63$.

Lloyd, J.W., \& deBettencourt, L.J.U. Academic strategy training: A manual for teachers. Charlottesville, VA: University of Virginia Learning Disabilities Research Institute, 1982.

Lloyd, J.W., Saltzman, N.J., \& Kauffman, J.M. Predictable generalization in academic learning as a result of preskills and strategy training. Learning Disability Quarterly, 1981, 4, 203-216.

Mercer, C.D., \& Mercer, A.R. The development and use of selfcorrecting materials with exceptional children. Teaching Exceptional Children, 1978, 11(1), 6-11.

Schwartz, T.A., Schwartz, R., \& Cohen, S.B. Teacher dissatisfaction and alienation as related to mainstreaming in education. Paper presented at the annual meeting of the American Educational Research Association, Boston, MA, April 10, 1980.

Sulzar-Azaroff, B., \& Mayer, G.R. Applying behavior-analysis procedures with children and youth. New York: Holt, Rinehart \& Winston, 1977.

White, O.R., \& Liberty, K.A. Behavioral assessment and precise educational measurement. In N.J. Haring \& R.L. Schiefelbusch (Eds.), Teaching special children. New York: McGraw-Hill, 1976. rather risque' magazine under a text. What are your possible actions? Which one will you choose, and why? Should you confiscate the magazine? If you determine who brought the magazine to class, what will you do? Is this a matter that should be reported to your principal? .... to the student's parents? What effects will your actions and responses have on each of the students? .... your principal/school?

This is one of 84 simulated situations that you may encounter, in areas categorized by behavior problems, health and safety, students' personal problems, dealing with parents, your personal life, and with the student teacher. The author is affiliated with the University of Florida and has taught at every level K-12. The 226-page paperback is published by Wadsworth, Belmont, CA. 